\title{
Carbohydrate Accumulation and Osmotic Stress in Cyanobacteria
}

\author{
By ROBERT H. REED, * DOUGLAS L. RICHARDSON, \\ STEPHEN R. C. WARR AND WILLIAM D. P. STEWART \\ Department of Biological Sciences, University of Dundee, Dundee DDI 4HN, UK
}

(Received 25 July 1983; revised 21 September 1983)

\begin{abstract}
In a comprehensive survey of the carbohydrate accumulation profiles of more than 70 strains of cyanobacteria three organic osmotica (glucosylglycerol, sucrose and trehalose) have been identified in both freshwater and marine isolates under conditions of osmotic stress. While the trend was towards glucosylglycerol accumulation in marine strains and sucrose accumulation in freshwater forms, there were no absolute differences between cyanobacteria isolated from each habitat. There was also no clear link between genus and the type of carbohydrate accumulated.
\end{abstract}

\section{INTRODUCTION}

Cyanobacteria (blue-green algae) are world-wide in distribution, occurring in saline and nonsaline habitats of diverse ionic composition (Fogg et al., 1973; Golubic, 1980). The division of these organisms into marine and freshwater forms has been frequently regarded as a useful means of distinguishing between taxa (Rippka et al., 1979; Stam \& Holleman, 1979). However, more emphasis is now being placed on the importance of various metabolic features as taxonomic markers in cyanobacteria. Recently it has been suggested that soluble organic compounds, accumulated as internal osmotica in response to salinity stress, may provide a major biochemical character which distinguishes marine (Mackay et al., 1983) and freshwater (Blumwald $e t$ al., 1983) forms. Thus glucosylglycerol has been considered to be 'unique' to. marine cyanobacteria (Mackay et al., 1983) while sucrose has been reported to accumulate in response to osmotic stress in freshwater cyanobacteria (Blumwald et al., 1983). Recently we demonstrated that the unicellular cyanobacterium Synechocystis sp. PCC 6803 (ATCC 27184), which was originally isolated from a freshwater habitat, was capable of growth both in freshwater and marine media and that, in response to osmotic stress, it produced glucosylglycerol as an internal osmoticum (Richardson et al., 1983). Subsequently we have examined over 70 strains of cyanobacteria to see whether any distinctions between the types of low molecular weight carbohydrates which are employed as osmotica in cyanobacteria isolated from marine and freshwater habitats could be identified.

\section{METHODS}

Cyanobacterial strains were obtained from the sources shown in Table $1 ;$ freshwater isolates were maintained in BG1 1 medium (Rippka et al., 1979) while marine strains were maintained in BG 11 medium $+3 \cdot 5 \%(w / v)$ sea salt (Gerrard Biological Centre, W. Sussex, UK). Carbohydrate accumulation profiles were obtained for marine cells exposed to salinities in the range $0 \cdot 5-5 \cdot 0^{\circ} \%(\mathrm{w} / \mathrm{v})$ sea salt; freshwater isolates were exposed to $\mathrm{NaCl}$ at concentrations up to $250 \mathrm{~mm}$, to determine whether soluble carbohydrate levels varied with osmotic stress.

Low molecular weight, ethanol soluble carbohydrates were assayed following extraction in boiling $80 \%$ ethanol, followed by overnight extraction in $80 \%$ ethanol at $20^{\circ} \mathrm{C}$. Samples were then dried using a rotary evaporator and stored in a vacuum desiccator for $24-48 \mathrm{~h}$ prior to analysis. Trimethyl silyl derivatives were prepared in pyridine (Reed et al., 1980); samples were analysed using a Varian 3700 gas chromatograph fitted with a $2 \mathrm{~m}$ column containing $2 \%$ SE52 on a diatomite support (Holligan \& Drew, 1971). Chromatograms were recorded and quantified using a Hewlett Packard HP3390A integrator. 

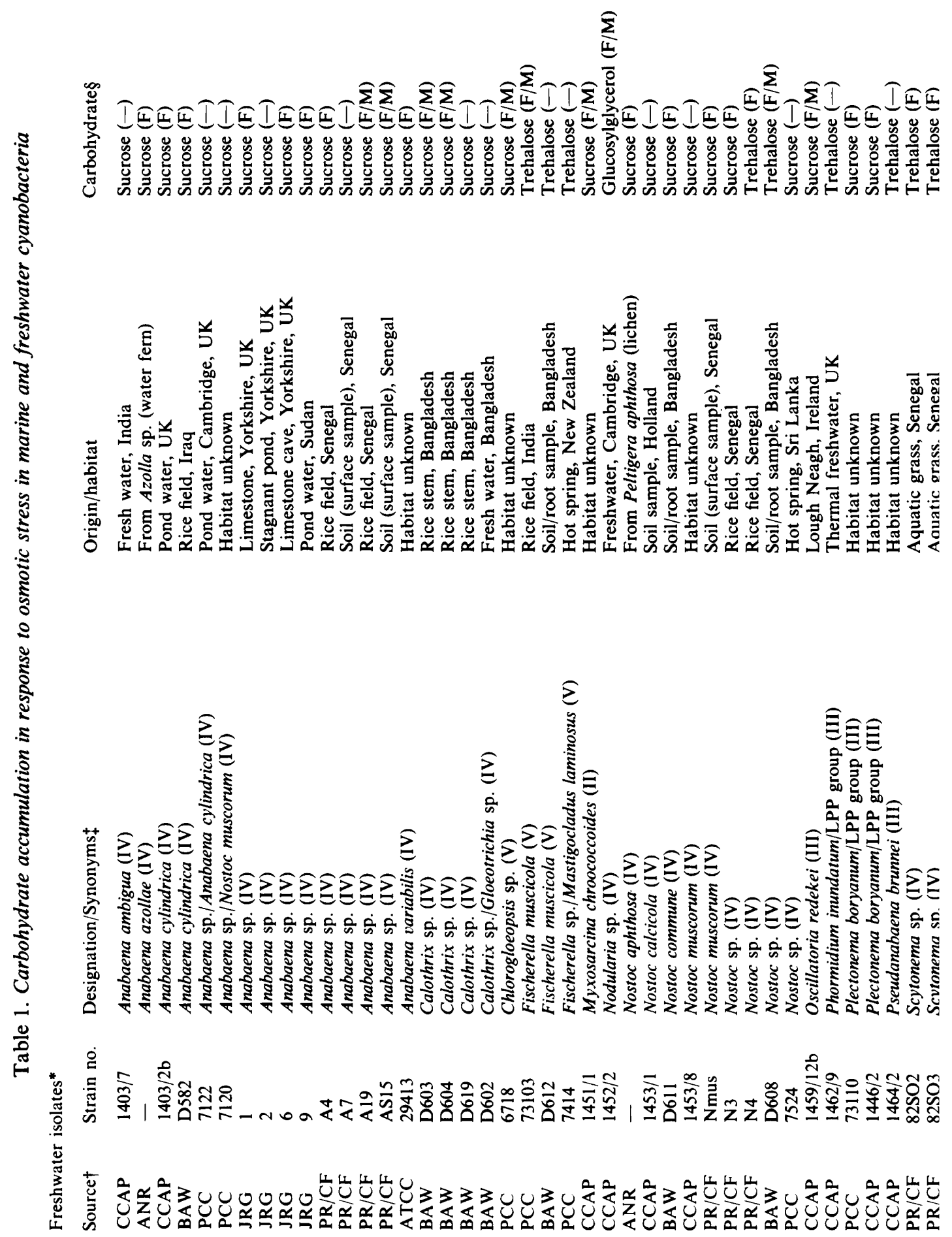

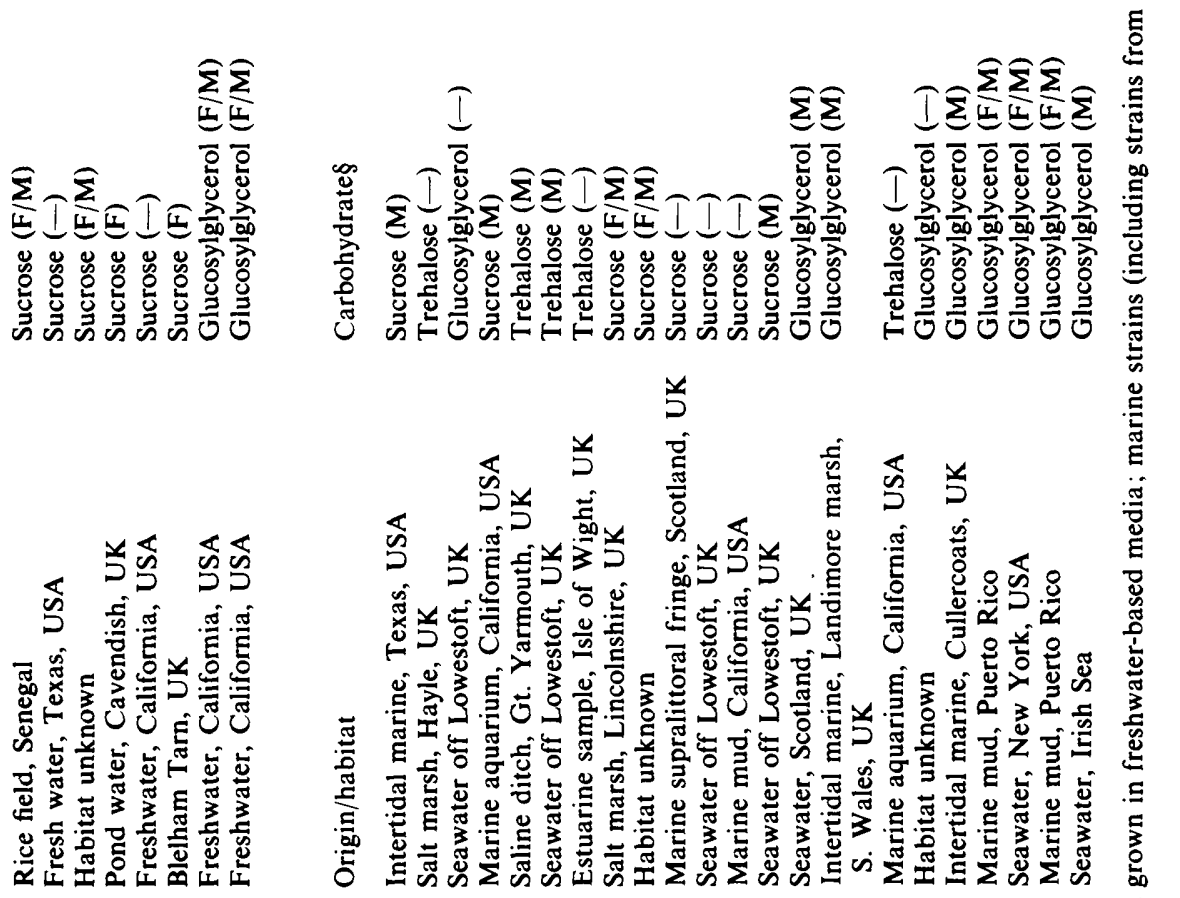



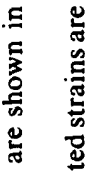

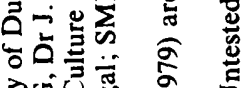

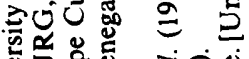

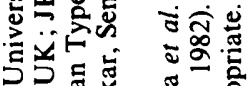





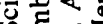

중요

ฮु





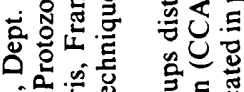

สิఖ



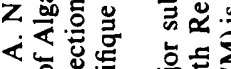

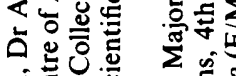

我若

乙吕造

这

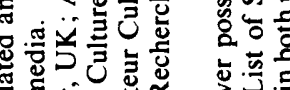

要

$\Theta$

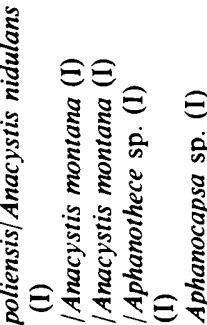

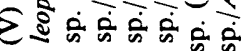

के 氖 氖氖

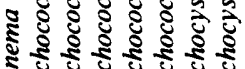
ธัँ केजिकेजक
$\widehat{\Xi}$

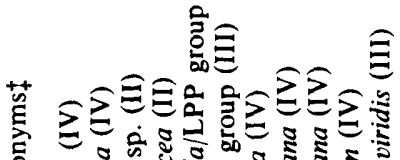

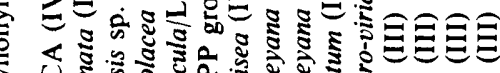

क U ज्ञ

के कि



eอิ

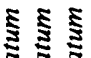

.

ㄴำ

每

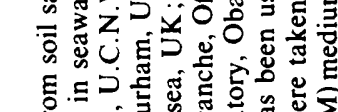



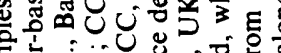

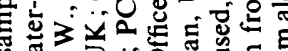



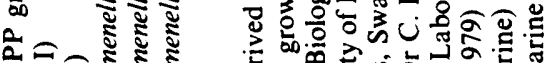

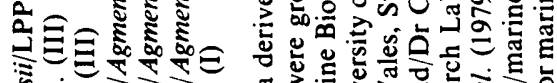

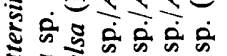



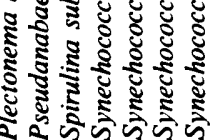

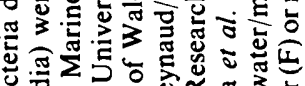

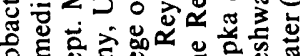

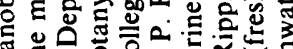
ठ‥





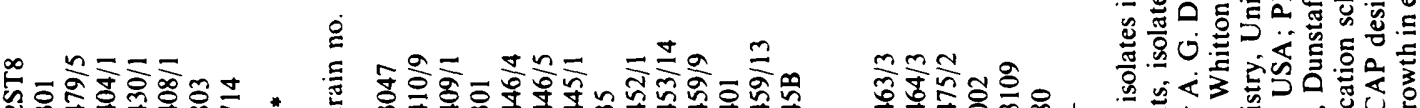

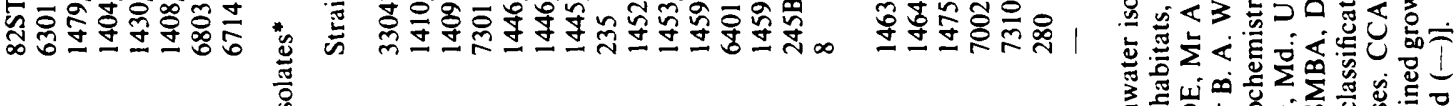

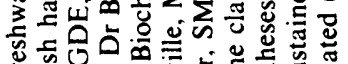






\section{RESULTS AND DISCUSSION}

All cultures grown in freshwater-based medium (BG11), including isolates which were originally derived from saline environments, had low intracellular soluble carbohydrate levels [usually $1-15 \mathrm{mmol}\left(\mathrm{kg} \mathrm{dry} \mathrm{wt}^{-1}{ }^{-1}\right.$ ] while seawater-grown cells all contained in excess of $100 \mathrm{mmol}(\mathrm{kg} \mathrm{dry} \mathrm{wt})^{-1}$. Both marine and freshwater isolates produced either glucosylglycerol (a nine-carbon heteroside; Kollman et al., 1979) which is structurally analogous to floridoside (galactosylglycerol) in the Rhodophyta (red algae), sucrose or trehalose (Table 1) in response to osmotic stress. In almost all cases (Table 1), a single carbohydrate represented more than $80 \%$ of the total soluble carbohydrate in any one strain.

No absolute correlation was found between soluble carbohydrate accumulation in response to salinity and genus, with different strains of each of the genera Calothrix, Nodularia, Nostoc, Plectonema, Pseudanabaena, Oscillatoria and Synechococcus showing different soluble carbohydrate accumulation profiles. Of the 22 marine isolates, $41 \%$ accumulated glucosylglycerol, $36 \%$ accumulated sucrose and $23 \%$ accumulated trehalose. Of the 49 freshwater isolates $76 \%$ accumulated sucrose in response to $\mathrm{NaCl}$ treatment, $18 \%$ accumulated trehalose and $6 \%$ accumulated glucosylglycerol. Thus, the trend is towards glucosylglycerol accumulation in marine isolates (as noted by Mackay et al., 1983) and sucrose accumulation in freshwater isolates in response to osmotic stress but there is no absolute correlation of taxonomic or ecological value. For example, three freshwater isolates accumulated glucosylglycerol while various marine isolates with an absolute requirement for $\mathrm{Na}^{+}$(Batterton \& Van Baalen, 1971) accumulated sucrose or trehalose, among which was the marine sucrose-accumulating Anabaena sp. CA which has a high $\mathrm{Na}^{+}$requirement for sustained growth (Stacey et al., 1977). Overall, the data suggest that it would be unwise to redefine and reclassify cyanobacteria solely on the basis of their carbohydrate accumulation profiles since there is no absolute relationship between either habitat or genus and the type of internal osmoticum accumulated in response to salt stress. Thus carbohydrate accumulation profiles appear to offer less to the cyanobacterial taxonomist than to his phycological counterparts (e.g. Kremer, 1980).

We are grateful to those who have provided us with cyanobacterial cultures, as detailed in Table 1. This research is supported by the Royal Society, NERC, SERC and ARC.

\section{REFERENCES}

Batterton, J. C. \& Van BaAlen, C. (1971). Growth responses of blue-green algae to sodium chloride concentration. Archiv für Mikrobiologie 76, 151-165.

Blumwald, E., Mehlhorn, R. J. \& PACKer, L. (1983) Studies of osmoregulation in salt adaptation of cyanobacteria with ESR spin-probe techniques. Proceedings of the National Academy of Sciences of the United States of America 80, 2599-2602.

Fogg, G. E., Stewart, W. D. P., Fay, P. \& Walsby, A. E. (1973). The Blue-Green Algae. New York: Academic Press.

GolUBIC, S. (1980). Halophily and halotolerance in cyanophytes. Origins of Life 10, 169-183.

Holligan, P. M. \& Drew, E. A. (1971). Routine analysis by gas-liquid chromatography of soluble carbohydrates in extracts of plant tissues. II. Quantitative analysis of standard carbohydrates and the separation and estimation of soluble sugars from a variety of plant tissues. New Phytologist 70, 270-297.

Kollman, V. H., Hanners, J. L., London, R. E., Adame, E. G. \& Walker, T. E. (1979). Photosynthetic preparation and characterization of ${ }^{13} \mathrm{C}$ labeled carbohydrates in Agmenellum quadruplicatum. Carbohydrate Research 73, 193-202.

KREMER, B. P. (1980). Taxonomic implications of algal photoassimilate patterns. British Phycological Journal 15, 399-409.
MACKay, M. A., Norton, R. S. \& BorowitzKa, L. J. (1983). Marine blue-green algae have a unique osmoregulatory system. Marine Biology 73, 301-307.

ReEd, R. H., Collins, J. C. \& Russell, G. (1980). The effects of salinity upon galactosylglycerol content and concentration of the marine red alga Porphyra purpurea (Roth.) C. Ag. Journal of Experimental Botany 31, 1539-1554.

Richardson, D. L., ReEd, R. H. \& Stewart, W. D. P. (1983). Synechocystis PCC 6803: a euryhaline cyanobacterium. FEMS Microbiology Letters 18, 99-102.

RipPKa, R., Deruelles, J., Waterbury, J. B., Herdman, M. \& Stanier, R. Y. (1979). Generic assignments, strain histories and properties of pure cultures of cyanobacteria. Journal of General Microbiology 111, 1-61.

Stacey, G., Van BaAlen, C. \& Tabita, F. R. (1977). Isolation and characterization of a marine Anabaena sp. capable of rapid growth on molecular nitrogen. Archives of Microbiology 114, 197-201.

Stam, W. T.\& Holleman, H. C. (1979). The influence of different salinities on growth and morphological variability of a number of Phormidium strains (Cyanophyceae) in culture. Acta botanica neerlandica 28, 45-66. 